\title{
Efficiency analysis for the production of modern energy carriers from renewable resources and wastes
}

\author{
K. J. Ptasinski \\ Department of Chemical Engineering, \\ Eindhoven University of Technology, The Netherlands
}

\begin{abstract}
Two global problems related to the use of fossil fuels are fast depletion and environmental damage. Biomass has a great potential as a clean renewable feedstock for producing modern energy carriers such as biodiesel, methanol, and hydrogen. However, the use of biomass is accompanied by possible ecological drawbacks such as limitations of land or water and competition with food production. For biomass-based systems, a key challenge is thus to develop efficient conversion technologies. This paper presents the efficiency analysis based on the Second Law of Thermodynamics for production of energy carriers from biomass. It is shown that the exergetic efficiency of renewable energy carriers is lower than that for fossil fuels. The highest efficiency is achieved for hydrogen production from high quality feedstock that is comparable with fossil fuels.
\end{abstract}

Keywords: renewable energy, biomass, second law analysis, exergy efficiency.

\section{Introduction}

The present world's energy demand is met by fossil fuels, i.e. petroleum, natural gas and coal. Two global problems related to the use of fossil fuels are a fast depletion and environmental damage due to emissions of various gases as $\mathrm{CO}_{\mathrm{x}}$, $\mathrm{SO}_{\mathrm{x}}$, and $\mathrm{NO}_{\mathrm{x}}$. In the future our energy systems will need to be renewable and sustainable, but also efficient, cost-effective and safe. It is widely acknowledged that the solution to the global problems would be to replace the existing fossil fuels by renewable energy (e.g. solar, wind and biomass). 
Biomass has several important advantages which can accelerate the transition to sustainable energy. Key feature are renewability, neutral $\mathrm{CO}_{2}$ impact, and unique versatility as a wide range of biomass sources can be used to make electricity and biofuels. However, the use of biomass is accompanied by possible ecological drawbacks, mainly limitation of land or water and competition with food production, Hanegraaf et al [1]. Moreover, agricultural production of biomass is relatively land intensive, and involves high logistics costs due to low energy density of biomass. Therefore an optimal utilization of biomass resources is desired. For biomass-based systems, a key challenge is thus to develop efficient biomass-to-biofuel conversion technologies.

Energy systems are traditionally analyzed by energetic analysis based on the First Law of Thermodynamics. However, this type of analysis shows only the mass and energy flows and does not take into account how the quality of the energy and material streams degrades through the process. In this paper the exergy analysis, which is based on the Second Law of Thermodynamics is used to analyze the conversion of biomass to biofuels.

The main purpose of this paper is to compare different biofuels for their production efficiency. The paper starts with an explanation of exergy concept in Section 2 as applied for biofuels evaluation. The following sections 3-5 present the efficiency analysis of conversion of various biomass feedstocks into biofuels such as biodiesel (Sections 3), methanol (Section 4), and hydrogen (Section 5). Finally, all biomass conversion processes are compared in Section 6.

\section{Exergy concept for efficiency evaluation}

Biomass cannot be directly used in modern energy systems but it must be converted into secondary energy carriers, mainly electricity and biofuels. This paper concerns the efficiency of biomass conversion into liquid and gaseous biofuels, such as biodiesel (Fischer-Tropsch hydrocarbons), methanol, and hydrogen. The main application of biofuels is in transportation but they can be also used as chemical commodity. In 2003 the EU Biofuel Directive set the target of $5.75 \%$ market share of biofuels that was recently increased to $10 \%$ in 2020 .

Various biomass feedstock and conversion technologies are available for biofuels production. A wide range of biomass sources, such as traditional agricultural crops, dedicated energy crops, residues from agriculture and foresting as well as organic wastes can be used. The most attractive biomass-tobiofuels conversion technologies involve thermochemical biomass conversion, mainly gasification. In this process biomass is converted at high temperature into syngas (mixture of $\mathrm{H}_{2}$ and $\mathrm{CO}$ ) which is subsequently used to produce various biofuels. Contrary to fossil fuels, there are numerous routes biomass-to-biofuel, characterized by various feedstocks, conversion processes and final products. The question what is addressed in this paper is how to select the most optimal biomass-to-biofuel conversion routes.

Exergy analysis is a relatively new method of thermodynamic analysis that has recently been applied in different fields of engineering and science, 
Szargut et al [2]. The exergy method takes into account not only the quantity of materials and energy flows, but also their quality as well. The main reason of exergy analysis is to detect and evaluate quantitatively the losses that occur in thermal and chemical processes. The exergy balance of a process can be represented in the following form using exergy values of all streams entering and leaving the process:

$$
\sum_{I N} \mathrm{E}_{j}+\mathrm{E}^{Q}+\mathrm{E}^{W}=\sum_{O U T} \mathrm{E}_{k}+I
$$

where $\sum_{I N} \mathrm{E}_{j}$ and $\sum_{O U T} \mathrm{E}_{k}$ are exergy flow of all entering and leaving material streams, respectively, $\mathrm{E}^{Q}$ and $\mathrm{E}^{W}$ are the sums of all thermal exergy and work interactions involved in a process.

The difference between the concept of exergy and those of mass and energy is that exergy is not conserved but subjected to dissipation. It means that the exergy leaving any process step will always be less than the exergy in. The difference between all entering exergy streams and that of leaving streams is called irreversibility $I$. Irreversibility represents the internal exergy loss in process as the loss of quality of materials and energy due to dissipation and it relates to entropy production $\Pi$ in the system:

$$
I=T_{o} \Pi
$$

The exergetic efficiency is defined as the ratio between useful exergy output from the process to the necessary exergy input to this process.

\section{Biodiesel (FT fuels) from wood}

The Fischer-Tropsch (FT) process has a lively history of about 70 years, as mentioned by Schultz [3]. In the FT synthesis, synthesis gas containing hydrogen and carbon monoxide are converted into liquid hydrocarbons:

$$
\mathrm{n} \mathrm{CO}+2 \mathrm{n} \mathrm{H}_{2} \rightarrow \quad\left[-\mathrm{CH}_{2}-\right]_{\mathrm{n}}+\mathrm{n} \mathrm{H}_{2} \mathrm{O} \quad \Delta \mathrm{H}=-159.2 \mathrm{~kJ} / \mathrm{mol}
$$

The most popular feedstock to provide synthesis gas for the FT process has varied through the years. During World War II, German vehicles were fuelled with coal-derived FT liquids. Today, natural gas is the most popular feedstock for synthesis gas production. Current developments focus on using biomass to produce clean FT fuels directly usable in the present transport sector.

Figure 1 shows a block diagram of a biomass gasification process integrated with FT synthesis (BIG-FT). The overall process has been modelled using the flowsheeting programme Aspen Plus which contains process models and property data, that is often used in early stages of process development. Sawdust is considered by Prins et al [4] as a feedstock which contains 9.3\% fixed carbon, 
$55 \%$ volatile matter, $0.7 \%$ ash and $35.0 \%$ moisture. The higher heating value of sawdust is $12.63 \mathrm{MJ} / \mathrm{kg}$. The biomass is dried to $10 \mathrm{wt} \%$ moisture by indirect drying using reaction heat from the Fischer-Tropsch section. Dried biomass is autothermally gasified with air at a temperature of $900^{\circ} \mathrm{C}$ and atmospheric pressure. The product gas is cooled to $90^{\circ} \mathrm{C}$, generating 50 bar and 20 bar steam, which are used in steam cycles for electricity production. The gas is subsequently cleaned, compressed to 25 bar and catalytically shifted in a watergas-shift (WGS) reactor. The gas is converted to gaseous and liquid hydrocarbons at a temperature of $260^{\circ} \mathrm{C}$ by cobalt-catalysed Fischer-Tropsch synthesis. The total single-pass $\mathrm{H}_{2}+\mathrm{CO}$ conversion is $80 \%$. The products from the FT reactor are cooled to $40^{\circ} \mathrm{C}$, so that hydrocarbon liquids are condensed from the tail gas, which contains most of the naphtha (C5-C8). Diesel (C9-C22) and wax $(\mathrm{C} 23+)$ are recovered as liquid products. These final products would be transported to a refinery for further work-up (e.g. fractionation, hydrocracking and/or hydroisomerisation). The tail gas from the FT work-up section is incinerated in a boiler and electricity is generated by means of a condensing steam turbine.

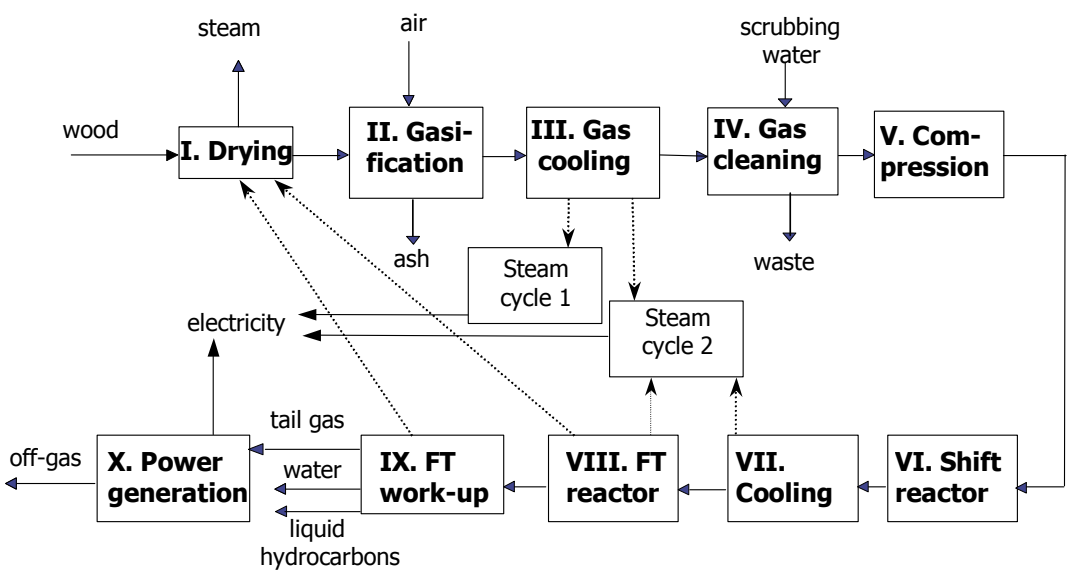

Figure 1: Schematics of a BIG-FT process.

The plant converts 57 ton/h of biomass into 5.6 ton/h of liquid FT products and 4.0 MW of electricity. The net output of hydrocarbon fuel is therefore $15.2 \%$ on weight basis. The exergy analysis shows that the biomass feed contains 210.8 MW exergy and the final liquid products contain $72.9 \mathrm{MW}$ with co-production of 4.0 MW of electricity The overall exergetic efficiency is calculated at $36.4 \%$, of which the exergy content of the liquid FT fuels is $34.5 \%$ of the exergy content in the biomass feedstock, while the electricity generated in the process amounts to $1.9 \%$ of the feed.

Figure 2 shows that the largest exergy losses occur in biomass gasification and generation of power from FT tail gas. The high exergy losses in the gasifier are due to large entropy generation as large wood molecules (cellulose) are 
converted into small molecules: $\mathrm{H}_{2}$ and $\mathrm{CO}$. The maximum thermodynamic efficiency can reach $46.2 \%$ provided gasification temperature is lowered to $700^{\circ} \mathrm{C}, \mathrm{C} 5-\mathrm{C} 8$ naphtha is included in the liquid FT product, and combined cycle is used for electricity generation. However, this optimal gasification temperature is rather low from the point of view of reaction kinetics in the gasifier.

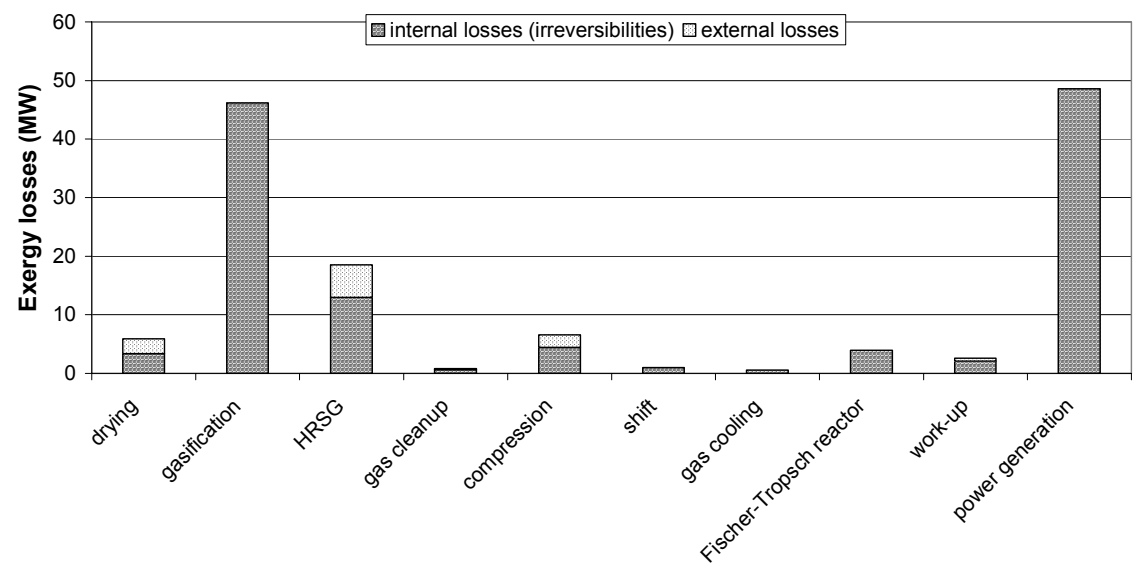

Figure 2: Exergy losses per process section for the BIG-FT plant.

\section{Methanol from sewage sludge}

At present, methanol is an important industrial chemical and may play a significant role as a synthetic fuel for the future. The important advantages of methanol as a fuel are a higher energy content per volume than the other alternative fuels and minimal changes in the existing fuel distribution network. Currently methanol is twice as cheaper as ethanol. Finally, methanol can considerably reduce automotive emissions and requires no antiknock alternatives because of its high octane number.

Presently the majority of methanol is made from natural gas, but also some methanol is made from coal, Macnaughton et al [5]. Both are converted into synthesis gas, via catalytic steam reforming in the case of natural gas, and through gasification in the case of coal. The further steps of the methanol plant are usually based on the ICI technology and include steps of syngas compression, methanol synthesis and distillation of crude methanol. Generally, methanol can be produced from any organic source including biomass, and municipal wastes.

Sewage sludge is a by-product of waste water purification and it contains a reasonably high fraction of organic material, which is rich in carbon - the main constituent of methanol. The second constituent of methanol, hydrogen, can be obtained from water present in wet sludge during the gasification process. Conversion of sewage sludge into methanol contributes more to sustainable technology than traditional sludge processing as dumping and incineration, Ptasinski et al [6]. 


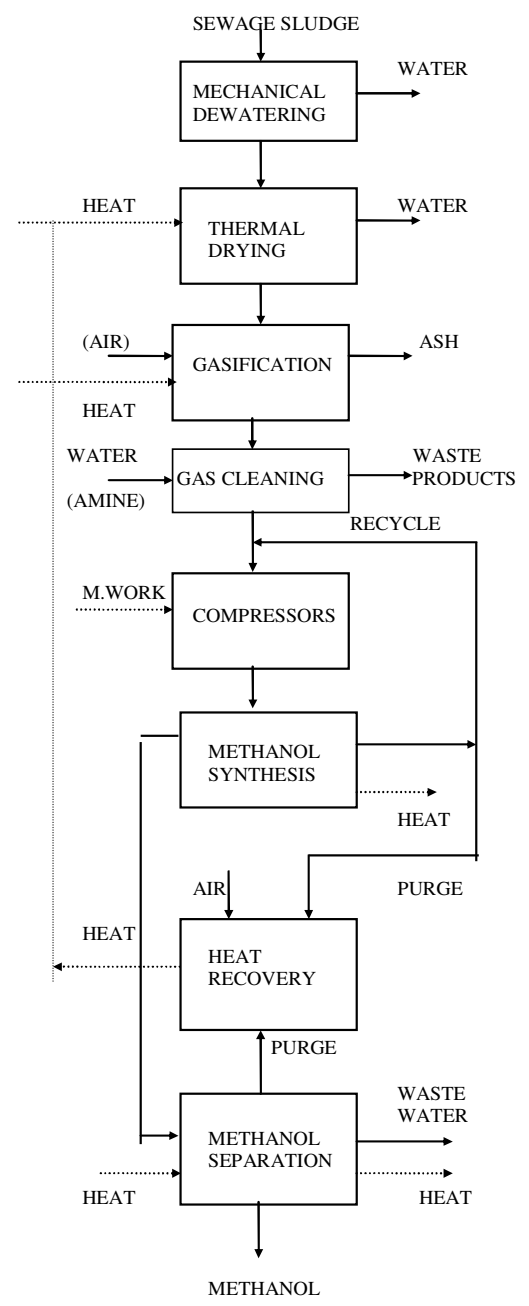

Figure 3: Schematics of the methanol-from-sludge process.

Figure 3 shows schematics of the proposed methanol-from-sludge process. The sludge from wastewater treatment contains only $1-2 \mathrm{wt} \%$ solids and is mechanically (up to $20 \mathrm{wt} \%$ ) and thermally dewatered (up to 55-100 wt \%). The solids contain $56 \%$ of organic materials which are rich in carbon $(50.4 \%)$, oxygen $(30.7 \%)$, and hydrogen $(6.9 \%)$. In the gasifier a synthetic gas is produced at temperature range of $800-1000^{\circ} \mathrm{C}$, containing mainly $\mathrm{CO}$ and $\mathrm{H}_{2}$. Next the syngas is cleaned from solid particles and gaseous components, and compressed to a pressure of 77 bar. The methanol synthesis is based on the ICI low pressure methanol process at temperature of $200^{\circ} \mathrm{C}$ according to chemical reactions:

$$
\mathrm{CO}+2 \mathrm{H}_{2}=\mathrm{CH}_{3} \mathrm{OH}
$$




$$
\mathrm{CO}_{2}+3 \mathrm{H}_{2}=\mathrm{CH}_{3} \mathrm{OH}+\mathrm{H}_{2}
$$

As the conversion of syngas to methanol cannot be completed in one pass, a recycle stream is used to increase the conversion efficiency. The last step is the methanol separation from dissolved gases and from water in a distillation column. A part of the recycle gas from the methanol synthesis and gas from the methanol separation is purged and combusted in a heat recovery unit.

The plant converts 50000 tons dry solids/year into 4300 tons methanol/year at gasifier temperature of $1000^{\circ} \mathrm{C}$ and a dry solid content of the sludge leaving the dryer of $80 \mathrm{wt} \%$. The net output of methanol is $8.6 \%$ on weight basis but on the exergy basis $22.8 \mathrm{MW}$ of sludge exergy is converted into $15.4 \mathrm{MW}$ of methanol exergy. The overall exergetic efficiency of this process is $56 \%$ when also the exergy of additional utilities is included. The total exergy losses are 14.8 MW that corresponds to $21 \mathrm{MJ} / \mathrm{kg}$ methanol. A breakdown by plant units of the total exergy loss is shown in Figure 4. Most of the exergy losses are associated with gasification, compression and thermal drying $(7.8 \mathrm{MJ} / \mathrm{kg}, 6.1 \mathrm{MJ} / \mathrm{kg}$ and 3.9 $\mathrm{MJ} / \mathrm{kg}$ methanol, respectively). The irreversibilities of other plant segments like heat recovery, methanol synthesis, methanol separation and gas cleaning are much smaller. The exergetic efficiency of this process is higher than that of thermal sludge treatment such as incineration. The technical feasibility of the proposed process should be demonstrated in a small-scale plant.

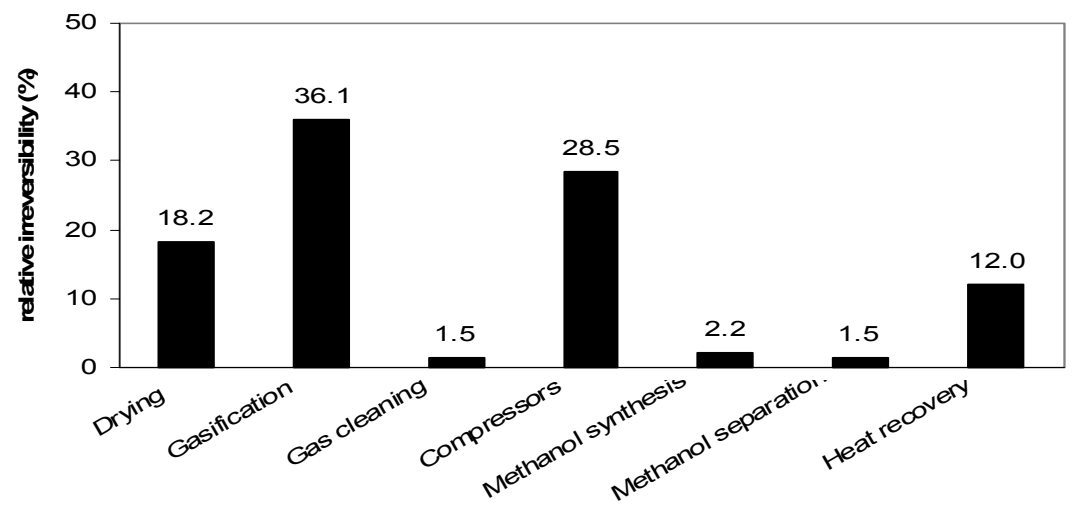

Figure 4: Exergy losses per process section for the methanol-from-sludge plant.

\section{Hydrogen from biomass and wastes}

Hydrogen is one of the most promising energy carriers for the future. It can be used as a fuel in fuel cells for power generation and in the transportation sector. The concept of hydrogen economy assumes only two energy carriers: hydrogen and electricity. Currently $95 \%$ of hydrogen comes from fossil fuels but biomass has the potential to become a sustainable source of hydrogen. Biomass-to- $\mathrm{H}_{2}$ conversion technologies can be divided into two categories: thermochemical and biochemical. 
246 Ecosystems and Sustainable Development VI

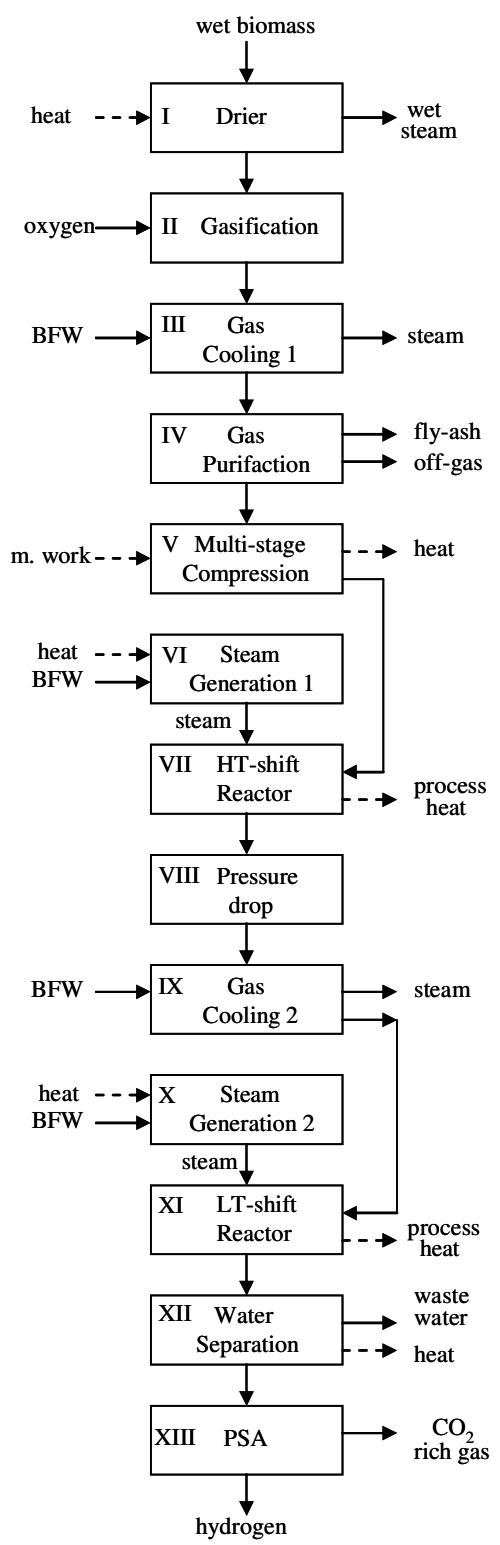

Figure 5: Schematics of the hydrogen-from-wood process.

The most widely practiced thermochemical process route for biomass-tohydrogen is gasification coupled with water gas shift, Ptasinski et al [7]. Figure 5 shows the flowsheet of the $\mathrm{H}_{2}$-from-wood process. The feed is wood which contains $78.4 \mathrm{wt} \%$ organic fraction, $19.8 \mathrm{wt} \%$ moisture and $1.84 \mathrm{wt} \%$ ash. The wood is first dried in the thermal drier to its final moisture content of $10 \mathrm{wt} \%$. 
The partially dried wood enters the gasifier, where a syngas containing $\mathrm{H}_{2}, \mathrm{CO}$, $\mathrm{CO}_{2}$ and $\mathrm{H}_{2} \mathrm{O}$ is produced at the temperature of $900^{\circ} \mathrm{C}$. The syngas leaving the gasifier is cooled down, cleaned, and compressed to 30 bar. In two water gas shift reactors $\left(400^{\circ} \mathrm{C}\right.$, and $150^{\circ} \mathrm{C}$, respectively) $\mathrm{CO}$ is subsequently converted into $\mathrm{H}_{2}$ due to reaction:

$$
\mathrm{CO}+\mathrm{H}_{2} \mathrm{O}=\mathrm{CO}_{2}+\mathrm{H}_{2}
$$

Water present in the gas leaving the shift reactors is separated in a flash unit at 20 bar and $25^{\circ} \mathrm{C}$ whereas $\mathrm{CO}_{2}$ is separated from $\mathrm{H}_{2}$ by pressure swing adsorption (PSA). Separation efficiency of $\mathrm{H}_{2}$ is $85 \%$ and $100 \%$ purity of hydrogen is produced.

This plant converts $1000 \mathrm{~kg} / \mathrm{h}$ wood into $76 \mathrm{~kg} / \mathrm{h}$ hydrogen and $1330 \mathrm{~kg} / \mathrm{h}$ $\mathrm{CO}_{2}$-rich gas. The net output of hydrogen on mass basis is thus $7.6 \%$ only. However, the exergy evaluation shows that $4.64 \mathrm{MW}$ of wood exergy is transformed into $2.54 \mathrm{MW}$ exergy of hydrogen and $0.61 \mathrm{MW}$ of $\mathrm{CO}_{2}$-rich gas. The overall exergetic efficiency of this process is $65.7 \%$ and $\mathrm{H}_{2}$ contributes in $71 \%$ to this efficiency. A breakdown by process units of the total exergy losses for this process is shown in Fig. 6 for different gasifier temperatures. The principal exergy losses occur in the gasifier and theses losses decrease with decreasing gasifier temperature.

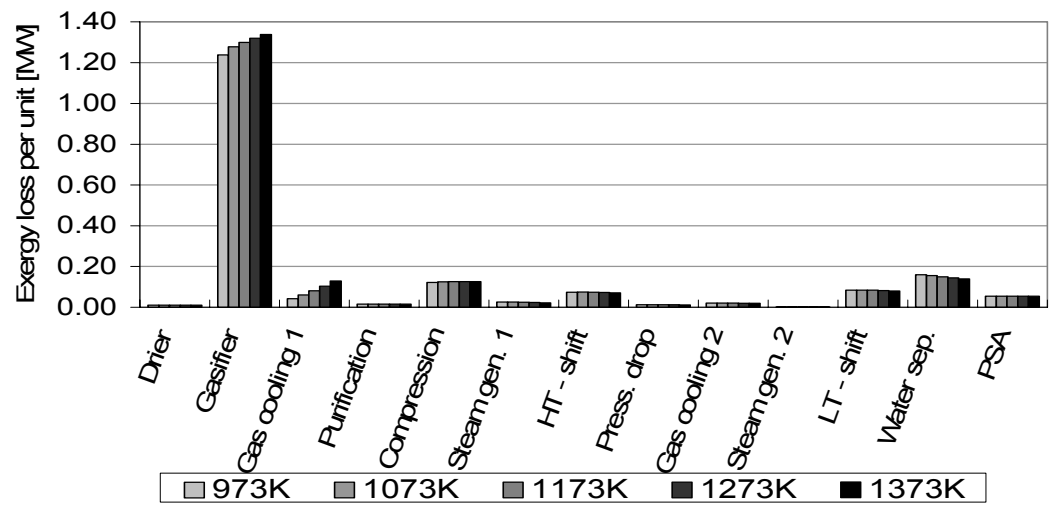

Figure 6: Exergy losses per process section for the hydrogen-from-wood plant.

Exergy analysis of thermochemical $\mathrm{H}_{2}$ production has been performed for other biomass feedstocks, including vegetable oil and manure, which contain various moisture content: 0 , and $43.6 \mathrm{wt} \%$, respectively. The results reveal that the exergetic efficiency decreases with increasing moisture content in the feedstock, as discussed in the next section.

Hydrogen can be produced from biomass also using biochemical processes such as fermentation and anaerobic digestion. The most promising is the combination of dark and photo fermentation. The plant using this process can 
convert $793 \mathrm{~kg} / \mathrm{h}$ of potato peels into $57 \mathrm{~kg} / \mathrm{h} \mathrm{H} \mathrm{H}_{2}$ that corresponds to exergetic efficiency of $29.1 \%$ [7]. Anearobic digestion is the most well-known technology for biochemical conversion of biomass into biogas containing $\mathrm{CH}_{4}$ and $\mathrm{CO}_{2}$ which can be further converted into $\mathrm{H}_{2}$ by a conventional technique such as steam methane reforming (SMR):

$$
\mathrm{CH}_{4}+2 \mathrm{H}_{2} \mathrm{O}=\mathrm{CO}_{2}+4 \mathrm{H}_{2}
$$

The anaerobic digestion plant Vagron [7] converts the wet organic fraction of the household waste, containing mainly kitchen and garden wastes, into a biogas containing $65 \% \mathrm{CH}_{4}$ and $35 \% \mathrm{CO}_{2}$ that can be further processed into $\mathrm{H}_{2}$ as shown above. The exergetic efficiency of biomass-to- $\mathrm{H}_{2}$ conversion in this process is $36.3 \%$.

\section{Discussion and conclusion}

Production of modern energy carriers such as biodiesel, methanol, and hydrogen from biomass can play a major role in future because it utilizes the renewable sources of energy. Very efficient biomass-to-biofuels conversion technologies should be developed due to ecological limitations set by biomass. Exergy analysis is a convenient tool for development and optimisation of future biomass processes. Exergy is regarded as the amount of ordered energy (work) present in biomass which should be conserved in produced biofuels as much as possible.

Table 1 summarizes exergetic efficiency of all biomass-to-biofuel routes considered in this paper. The exergetic efficiency for hydrogen-from-natural-gas process is also reported in this table, as a typical value for fossil fuels, Rosen [8]. All reported biomass routes have lower exergetic efficiency compared to fossil fuels. The highest efficiency is for hydrogen-from-biomass processes from high quality feedstocks, such as wood or vegetable oil. The latter feedstock, which is carbon-rich and moisture-free, can compete with fossil fuels.

Table 1: $\quad$ Exergetic efficiency for biomass-to-biofuel processes.

\begin{tabular}{|l|l|l|c|}
\hline Process & Biomass feed & Biofuel & Exergetic efficiency (\%) \\
\hline Fischer-Tropsch & sawdust & biodiesel & 36.4 \\
\hline Methanol-from sludge & sewage sludge & methanol & 56.0 \\
\hline Gasification & wood & hydrogen & 65.7 \\
\hline Gasification & vegetable oil & hydrogen & 79.1 \\
\hline Gasification & manure & hydrogen & 35.8 \\
\hline Fermentation & potato peels & hydrogen & 29.1 \\
\hline Anaerobic digestion & household waste & hydrogen & 36.3 \\
\hline SMR & natural gas & hydrogen & 78.0 \\
\hline
\end{tabular}

The conversion efficiency of all investigated biomass-to-biofuel routes can be increased by improving the operation of biomass gasifier, which shows the highest exergy losses in all considered processes. Finally, the exergy concept applied in this paper is based on thermodynamics and therefore it is very 
fundamental. However, more complex sustainability criteria should be also applied in order to cover other aspects such as environmental, social, en economical.

\section{References}

[1] Hanegraaf, M.C., Biewinga, E.E. \& van der Bijl, G., Assessing the ecological and economic sustainability of energy crops. Biomass and Bioenergy, 15, pp. 345-355, 1998.

[2] Szargut, J., Morris, D.R. \& Steward, F.R., Exergy Analysis of Thermal, Chemical and Metallurgical Processes, Springer Verlag: Berlin, 1988.

[3] Schulz, H., Short history and present trends of Fischer-Tropsch synthesis. Applied Catalysis A-General, 186, pp. 3-12, 1999.

[4] Prins, M.J., Ptasinski, K.J. \& Janssen, F.J.J.G., Exergetic optimisation of Fischer-Tropsch fuels from biomass. Fuel Processing Technology, 86, pp. 375-389, 2004.

[5] Macnaughton, N.J., Pinto, A. \& Rogerson, P.L., Development of methanol technology for future fuel and chemical markets. Energy Progress, 7, pp. 232-241, 2002.

[6] Ptasinski, K.J., Hamelinck, C. \& Kerkhof, P.J.A.M., Exergy analysis of methanol from the sewage sludge process. Energy Conversion \& Management, 43, pp. 1445-1457, 2002.

[7] Ptasinski, K.J., Prins, M.J. \& van der Heijden, S.P., Exergy analysis of hydrogen production methods from biomass. Proc. of the 19th Int. Conf. ECOS2006, eds. C.A. Frangopoulos, C.D. Rakopoulos \& G. Tsatsaronis, NTUA: Athens, pp. 1601-1608, 2006.

[8] Rosen, M.A., Thermodynamic comparison of hydrogen production processes. Int. J. Hydrogen Energy, 21, pp. 349-365, 1996. 